\title{
COPING STYLE AS A PSYCHOLOGICAL RESOURCE OF GRATEFUL PEOPLE
}

\author{
ALEX M. WOOD \\ University of Warwick \\ STEPHEN JOSEPH \\ University of Nottingham \\ P. ALEX LINLEY \\ Centre for Applied Positive Psychology
}

\begin{abstract}
We examined whether gratitude was correlated with distinct coping styles, and whether coping styles mediated the relationship between gratitude and well-being. Participants $(n=236)$ completed measures of coping styles, dispositional gratitude, and measures of well-being. Gratitude correlated positively with seeking both emotional and instrumental social support, positive reinterpretation and growth, active coping, and planning. Gratitude correlated negatively with behavioural disengagement, self-blame, substance use, and denial. Coping styles mediated up to $51 \%$ of the relationship between gratitude and stress, but did not substantially mediate the relationship between gratitude and either happiness, depression, or satisfaction with life. We suggest that different mechanisms relate gratitude to separate aspects of well-being. Further research is indicated into the role of gratitude in social support processes, and in growth following adversity.
\end{abstract}

Psychological research into gratitude as an individual difference variable seems poised to become a major influence on the field of personality psychology (McCullough, Emmons, \& Tsang, 2002; Wood, Joseph, \& Linley, 2007). Research has suggested that gratitude has one of the highest correlations with well-being of almost any personality characteristic (Park, Peterson, \& Seligman, 2004), and it seems to play an important part in

\footnotetext{
The authors are grateful for the generous assistance of Liz Blagrove with data collection, and Neil Stewart for his valuable advice on the manuscript. This research was supported by a University of Warwick Research Fellowship awarded to the first author.

Correspondence should be addressed to Alex M. Wood, Department of Psychology, University of Warwick, England, UK. CV4 7AL. E-mail: alex.wood@warwick.ac.uk
} 
people's lives, with $67 \%$ reporting expressing gratitude "all of the time", and a further $60 \%$ reporting that that expressing gratitude made them feel "very happy" (Gallup, 1999). Traditionally, there has been a substantial disparity between the small amount of consideration given to gratitude within psychology and the substantial consideration provided in philosophical and religious literatures (Emmons \& Crumpler, 2000; Harpman, 2004; McCullough, Kilpatrick, Emmons, \& Larson, 2001). However, partially influenced by the positive psychology movement (Linley, Joseph, Harrington, \& Wood, 2006; Seligman \& Csikszentmihalyi, 2000), research into dispositional gratitude is now receiving considerable attention. Given the novelty of gratitude research, most existing work has focused only on the emotional benefits of dispositional gratitude (Emmons \& McCullough, 2003; McCullough et al., 2002), and has not yet focused on the potential cognitive resources of grateful people, or on the mechanisms whereby gratitude is related to well-being. In this paper we investigate whether dispositional gratitude is associated with adaptive coping strategies, and whether this relationship could explain why grateful people seem to have higher levels of well-being.

Evidence that gratitude is related to well-being is growing. Correlational studies have found consistently that dispositional gratitude is strongly linked to well-being. McCullough et al. (2002) found that gratitude was positively related to life satisfaction, vitality, and happiness, and negatively related to depression, and envy, all in the absolute range of $r=$ .30 to .51 . Further, these relationships exist independently of the effects of both the Big Five personality traits and social desirability (as measured by the BIDR; Paulhus, 1998), and persist when gratitude is measured via peer rating. Park, Peterson \& Seligman (2004) found that of all the 24 VIA character strengths (Peterson \& Seligman, 2004), gratitude was more strongly related to life satisfaction $(r=.43)$ than all of the other strengths except hope/optimism and zest (with the latter arguably a direct measure of happiness). Notably, this suggests that gratitude can explain more variance in life satisfaction than such traits as love, forgiveness, social intelligence, and humour. Additionally, McCullough, Tsang, and Emmons (2004) found that daily experiences of gratitude were related to a host of well-being benefits. Evidence regarding the relationship between gratitude and well-being is also provided by three experimental, longitudinal studies, which showed that if participants are manipulated into focusing on the good in their lives for a number of weeks, there are substantial improvements in happiness, depression, and even physical health (Emmons \& McCullough, 2003; Lyubomirsky, Sheldon, \& Schkade, 2005; Seligman, Steen, Park, \& Peterson, 2005). Such findings suggest that the relationship between gratitude and well-being may be causal. 
Although research looking at the emotional benefits of the grateful personality is growing, existing studies have not really focused on whether more grateful people have better psychological resources. One psychological resource that people can possess is an adaptive coping style (Ptacek \& Gross, 1997). A vast psychological literature exists regarding coping (Somerfield \& McCrae, 2000), and various multidimensional conceptions of broad coping strategies have been developed (Schwarzer \& Schwarzer, 1996), such as the COPE (Carver, Scheier, \& Weintraub, 1989). Although there the coping literature is substantial, to our knowledge the role of gratitude has not yet been considered. It is possible that grateful people exhibit a distinct pattern of coping strategies, in particular the habitual seeking out of emotional and instrumental social support. More generally, Fredrickson, Tugade, Waugh, and Larkin (2003) showed that following the September 11th terrorist attacks, a composite measure of positive emotions (including gratitude) buffered the depressive reactions of resilient people, and suggested further work examining the link between positive emotions and coping.

A theoretical rationale for why dispositional gratitude may be related to coping strategies is presented by Fredrickson (2004), who suggests that as gratitude is a positive emotion, and that frequent experiences of gratitude will build enduring cognitive resources. According to the broaden-and-build theory (Fredrickson, 1998, 2001), positive emotions are adaptive evolutionary mechanisms which broaden thought-action repertoires, improving creativity and cognitive ability (Fredrickson \& Branigan, 2005; Johnson \& Fredrickson, 2005). Positive emotions are adaptive as they encourage the person to make use of the 'good times' - occasions when the person is not in any threat or danger. Rather than idly passing the time, positive emotions encourage people to engage in cognitive and behavioural activities that will build resources that will become useful during future threatening and stressful occasions (Fredrickson, 1998, 2001). Given that gratitude seems to have a positive affective valence (Gallup, 1999), Fredrickson (2004) has suggested that the broaden-and-build theory could offer a wider view on dispositional gratitude, and that through broaden-and-build processes grateful people will have developed superior social and cognitive resources such as positive coping responses.

The social and cognitive benefits derived through broaden-and-build processes arising from experiencing a given positive emotion are thought to be partially dependant on the inherent nature of the emotion. For example, joy leads to reflection and schematic integration, interest leads to exploratory behaviour (Fredrickson, 2000). As a state, gratitude seems to have a 'moral' or pro-social nature (Bartlett \& DeSteno, 2006; McCullough et al., 2001; Tsang, 2006), involving recognition of benefits received (Tesser, Gatewood, \& Driver, 1968). As a disposition, gratitude 
has been shown to relate to such traits as extraversion, agreeableness, forgiveness, and empathy (McCullough et al., 2002). Peer reports of a person's level of gratitude have also been shown to be linked to peer perceptions of other pro-social tendencies (McCullough et al., 2002). We expect gratitude to be linked with coping strategies utilising social support. If grateful people are more aware of the benefits they receive, then they may more consciously realise that people are willing to help them, making them more likely to seek out social support in times of need.

At a more general level, we expected grateful people to use coping strategies broadly characterised by approach rather than disengagement strategies. Grateful people appear to view the world as a generally more pleasant place, taking the time to focus on the positive aspects of life (Adler \& Fagley, 2005; Watkins, Woodward, Stone, \& Kolts, 2003). This perception of the world as a hospitable place may likely lead to an increased willingness to deal actively with problems. For example, when people view the world as threatening (for example, in the case of anxiety disorders) they are likely to exhibit inhibition tendencies (Beck, 1976). In contrast, we expect grateful people to view the world as a pleasant place, and expect this to be reflected in coping strategies involving less inhibition and more active cognitive and behavioural actions.

Given that certain coping strategies are related to well-being, possessing adaptive coping strategies could explain the emotional benefits of having a grateful disposition. Gratitude is related to such traits as optimism (McCullough et al., 2002), and it is known that adaptive coping is one mechanism through which optimism is related to well-being (Brissette, Scheier, \& Carver, 2002). In this paper we investigate whether coping mediates the relationship between gratitude and well-being. While existing studies have made the (possibly causal) link most clearly, what is not clear is the process or intervening variables in this relationship. If mediation could be shown, then there would be a clear suggestion of why gratitude is related to well-being. If mediation cannot be shown, then the results will suggest that gratitude is related to well-being through different mechanisms than related traits such as optimism. The latter possibility will support conceptions of gratitude as a unique emotion, with a unique role in people lives (McCullough et al., 2002; McCullough et al., 2001).

Establishing that gratitude is linked with coping will also begin to integrate the predominantly social literature of gratitude with the more clinical literature on coping and distress. At a broad level, psychology would benefit from a greater integration of its sub-disciplines (Sternberg \& Grigorenko, 2001). At a more specific level, we have argued elsewhere (Joseph \& Linley, 2006; Linley et al., 2006) that a key benefit of the positive psychology movement is that it provides impetus for an integration of research into the positive and negative aspects of life. Grati- 
tude seems to be critically placed to aid in such a process of integration, as on the one hand it is a positively valanced emotion involved in social life (Bartlett \& DeSteno, 2006; Tsang, 2006), and on the other has recently been shown to have the potential to form the basis of a powerful new therapy to alleviate psychological suffering (Bono, Emmons, \& McCullough, 2004; Emmons \& McCullough, 2003; Lyubomirsky et al., 2005; Seligman et al., 2005). Positive approaches such as gratitude interventions have much to offer clinical therapies (Duckworth, Steen, \& Seligman, 2005), and aid in promoting a more positive and realistic theoretical reconceptualisation of distress (Maddux, 2002; Maddux, Gosselin, \& Winstead, 2005; Maddux, Snyder, \& Lopez, 2004). Establishing a relationship between gratitude and coping would suggest new directions for research into gratitude interventions. Currently the research has focused on showing emotional benefits of the interventions. Showing that gratitude is related to coping will raise the question of whether gratitude interventions additionally increase adaptive coping, and indicate research into use with client groups for whom adaptive coping is particularly important.

In this paper, we aimed to establish whether gratitude is related to distinct coping strategies, and whether the relationship between gratitude and well-being is mediated by coping strategies. We report the findings from two samples. The samples differ in whether the full or brief measures of coping were used, and in the aspects of well-being studied. The advantage of this approach is that it allows a broader range of the aspects of well-being to be studied, as well as allowing replication of each sample's findings. To avoid needlessly reproducing tables, and thus impairing clarity, we present the results of these two samples simultaneously throughout this paper.

\section{METHOD}

\section{PARTICIPANTS}

Two hundred and thirty six people were surveyed across two samples. In the first sample, 149 people (115 female, 33 male, one undisclosed) voluntarily participated during a second year psychology lecture. All were aged between 18 and 22 years, and were predominantly white $(92 \%)$. In the second sample, 87 people (75 female, 12 male) voluntarily participated during a first year psychology lecture. Ages ranged from 18 to 30 years, with $94 \%$ under 22 years. The sample was predominantly of a white ethnic background (81\%), with the next highest represented ethnicity being Indian (9\%). 


\section{MEASURES}

In both samples, Gratitude was assessed using the Gratitude Questionnaire 6 (GQ6; McCullough et al., 2002). This measures trait gratitude through self-reports of items that measure emotional intensity (e.g. "I feel thankful for what I have received in life"), frequency (e.g. "Long amounts of time can go by before I feel grateful to something or someone"), and density, or the number of events or people that can elicit the emotion (e.g. "I am grateful to a wide variety of people"). Six items (two reverse coded) are rated on a seven point scale, ranging from 1 (strongly disagree) to 7 (strongly agree), which are summed to give a single score between 6 and 42 .

The trait version of the full COPE (Carver et al., 1989) was used to measure coping in Sample 2. This asks respondents about the coping strategies they generally use during periods of stress. Sixty items assess 15 conceptually different forms of coping, including styles generally involving adaptively approaching the adversity (active coping, seeking instrumental support, seeking emotional support, suppression of competing activities, planning, and positive reinterpretation and growth) generally maladaptivly withdrawing from the problem (denial, behavioural disengagement, alcohol and drug use, and mental disengagement), and other common strategies which do not clearly fall into either category (restraint, acceptance, turning to religion, humour, and focus on venting emotions). Each of the sub-scales has good internal validity, and extensive psychometric development (Carver et al., 1989).

The Brief COPE (Carver, 1997) was used to measure coping in Sample 1. It was developed as a shorter and alternative form of the COPE, from the author's experience of participant dissatisfaction with the length of the original scale. On the basis of past research, the sub-scales of restraint coping and suppression of competing activities were omitted; the former because of lack of empirical evidence of its value, and the latter because of substantial redundancy with active coping. Self-blame is also assessed in this version, as more recent empirical work has shown it to be a maladaptive coping strategy. Apart from these possible improvements, the Brief COPE shows a remarkably similar factor structure to the COPE, and measures the same dimensions (Carver, 1997). The Brief COPE contains 28 items, and has acceptable internal reliability.

Perceived stress was measured using the 10-item Perceived Stress Scale (Cohen \& Williamson, 1988) (see also Cohen, Kamarck, \& Mermelstein, 1983). The PSS measures the extent to which participants find their lives unpredictable, uncontrollable, and overwhelming. Scores can range from 0 to 56, with higher scores representing more stress.

Depression was measured using the Centre for Epidemiologic Studies Depression scale (CES-D'; Radloff, 1977). The CES-D was designed for 
measuring depressive symptoms in the general population, and contains 20 items relating to depressed affect, positive affect (reverse coded), and somatic and retarded activity. Participants rate how frequently the have felt a certain way during the past week on a four point scale $(0=$ rarely or none of the time, $1=$ some or a little of the time, $2=$ occasionally or a moderate amount of time, $3=$ most or all of the time). Possible scores range from 0 to 60 .

Happiness was measured using the Short Depression - Happiness Scale (SDHS: Joseph, Linley, Harwood, Lewis, \& McCollam, 2004). The SDHS was designed to extend existing measures of depression beyond the zero point to measure not only the absence of depression but also the presence of happiness. The SDHS consists of six items, three items measuring happiness (e.g., I felt happy) and three reverse coded items measure depressive states (e.g., I felt my life was meaningless). Participants rate how frequently the feel the way described in the item on a four point scale $(0=$ never, $1=$ rarely, $2=$ sometimes, $3=$ often $)$. When the items are totalled, people can score from 0 (depressive state) through 9 (neither unhappy or happy) to 18 (very happy).

The Satisfaction with Life Scale (SWLS; Pavot \& Diener, 1993) was used as a measure of the cognitive evaluation dimension of happiness. Whereas the SDHS focuses on frequency of positive affect, the SWLS focuses on the cognitive component of positive affect, with such items as "In most ways my life is close to ideal". The SWLS has a degree of temporal stability ( $r=.54$ over 4 years), whilst still being highly responsive to the effect of psychological therapies (Pavot \& Diener, 1993).

\section{PROCEDURE}

In Study 1 participants completed the GQ-6, Brief Cope, SWLS, and Perceived Stress Scale (PSS). In Study 2 participants completed the GQ-6, the full COPE, CES-D, and SDHS. For both studies, questionnaires were distributed at the start of a lecture and were completed during the first few minutes of class time. Efforts were made to maintain silence during this period. Participants were told that participation was completely voluntary, and although the research was important, they were free not to participate without penalty.

\section{RESULTS}

TESTING THE RELATIONSHIP BETWEEN GRATITUDE AND COPING STRATEGIES

In order to see how much variance was shared between coping style and 
gratitude we conducted multiple regressions of gratitude onto all of the scales contained in each of the coping styles questionnaires. Coping styles accounted for a substantial proportion of the variance in gratitude in both Sample 1 (Multiple $R=.59, F(14,134)=5.10, p<.001$ ) and Sample 2 (Multiple $R=.59, F(15,62)=2.20, p<.05)$. As the coping styles are theoretically and empirically highly correlated, we did not examine the unique contribution of each coping style, because issues of multicollinearity would have prevented meaningful interpretation (Gordon, 1968).

When gratitude was correlated with each coping strategy, a substantially similar picture emerged between the two studies (see Table 1). Gratitude was positively correlated with instrumental social support, emotional social support, positive reinterpretation and growth, active coping, and planning, and negatively correlated with behavioural disengagement, self-blame, substance use, and denial. However, the correlations between denial and gratitude, and planning and gratitude only approached significance in Sample 1, and gratitude was only correlated with substance use in Sample 1.

\section{TESTING THE RELATIONSHIP BETWEEN GRATITUDE AND WELL-BEING}

We attempted to replicate earlier work showing that gratitude was related to well-being. As can be seen from Table 2 gratitude is significantly related to stress, happiness, depression, and satisfaction with life (range $r=.41$ to .59). As with previous research, gratitude was shown to be strongly related to each of the well-being indicators used in the study.

\section{TESTING THE RELATIONSHIP BETWEEN} COPING STRATEGIES AND WELL-BEING

In order to see whether coping styles could predict well-being in the current sample we conducted a series of separate multiple regressions with the coping strategies as predictor variables, and the well-being measures as criterion variables. In each case, the Multiple Rs ranged from .53 to .71 (all $p<.001$ ), indicating that coping styles were significantly associated with well-being in the current samples. Again we did not examine the unique contributions of the coping styles on well-being due to issues of multicollinearity. 


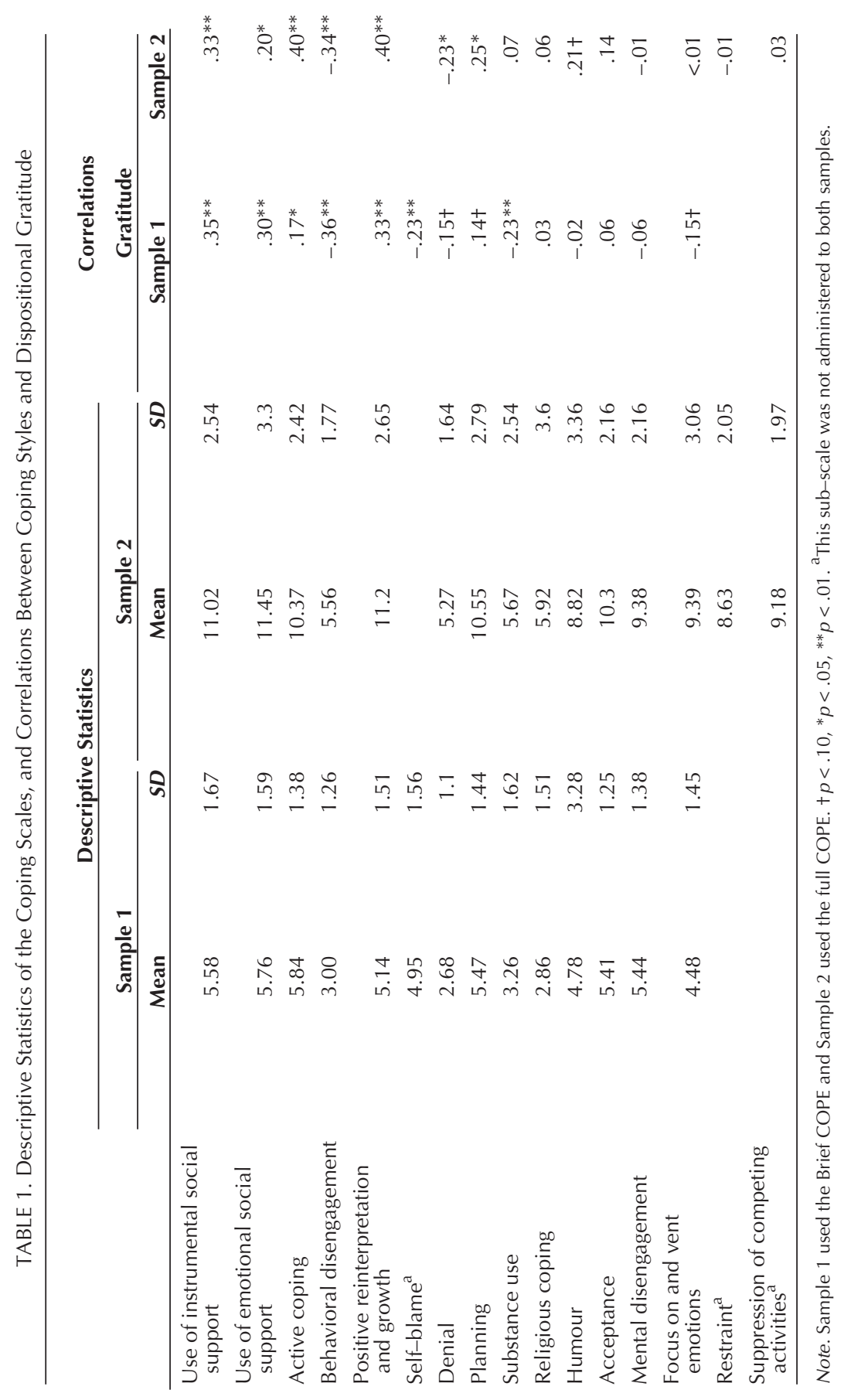

1084 


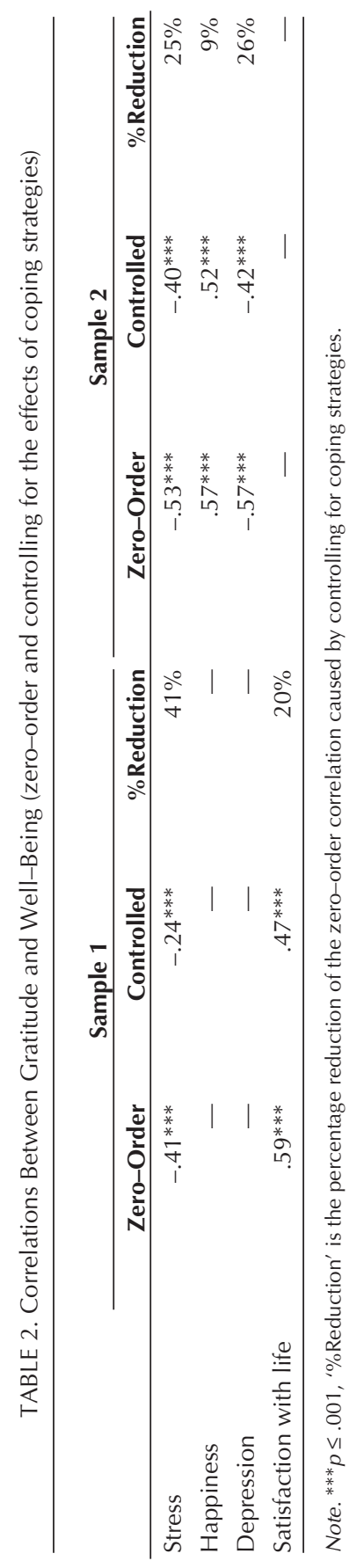

1085 
TESTING WHETHER COPING MEDIATES THE RELATIONSHIP BETWEEN GRATITUDE AND WELL-BEING

We separately tested whether coping styles mediated the relationship between (a) gratitude and stress, (b) gratitude and happiness, (c) gratitude and depression, and (d) gratitude and satisfaction with life. Baron and Kenny (1986) provide four steps which are necessary to show mediation. First, the predictor (gratitude) must be related to the outcome (the well-being measure). Second, the predictor (gratitude) must be related to the mediators (coping styles).Third, the mediators (coping styles) must be related to the outcome (well-being) after controlling for the predictor. Finally, in the fourth step, full mediation is shown if the relationship between the predictor (gratitude) and the outcome (the well-being measure) is no longer be statistically significant after controlling for the mediator. Partial mediation is shown if both the relationship between the predictor (gratitude) and the outcome (the well-being measure) is reduced in magnitude, and the mediated pathway is statistically significant (as assessed by Sobel's 1982 test, see Baron \& Kenny, 1986; Kenny, Kashy, \& Bolger, 1998).

Table 2 shows that when all of the coping styles were controlled, the relationship between gratitude and each of the well-being indicators remained statistically significant, ruling out full mediation (Step 4). There was however some reduction in the size of the correlation between gratitude and well-being after controlling for coping styles (ranging from $9 \%$ to $41 \%$ ), suggesting that partial mediation may have occurred.

To begin testing for the significance of partial mediation, and to see which of the coping strategies were responsible any mediation, for each of the well-being measures we separately tested whether each of the coping strategies individually acted as a partial mediators, using the four steps outlined above.

None of the coping measures were found to significantly mediate the relationship between gratitude and either happiness or depression. However, Self-blame provided a small partial mediation of the relationship between gratitude and satisfaction with life (11\% mediation, $z=$ $2.45, p<.05)$.

Regarding stress, in Sample 2, the gratitude and stress relationship was partially mediated by positive reinterpretation and growth only (18\% mediation, $z=2.08, p<.05)$. However, in Sample 1, the relationship between gratitude and stress was partially mediated by behavioural disengagement ( $26 \%$ mediation, $z=3.03, p<.01)$, positive reinterpretation and growth $(26 \%$ mediation, $z=3.06, p<.01)$, and self-blame ( $22 \%$ mediation, $z=2.61, p<.01)$. 


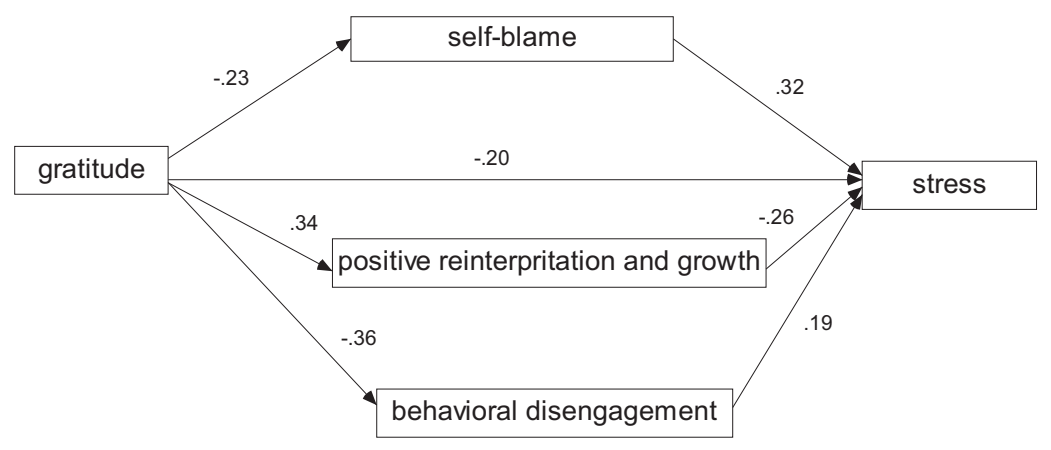

FIGURE 1. Path diagram of coping partially mediating the relationship between gratitude and stress in Sample 1.

Given that three coping strategies individually mediated the relationship between gratitude and stress in Sample 1, we examined whether they could provide joint mediation. The results of this analysis are shown in Figure 1. Each of the mediated paths remained significant (smallest $z=2.21$, all $p<.05$ ). Together behavioural disengagement, positive reinterpretation and growth, and self-blame mediated $51 \%$ of the relationship between gratitude and stress in Sample 1.

\section{DISCUSSION}

The results showed correlations between gratitude and several coping strategies, as well as several indicators of well-being. Coping strategies appeared to mediated up to $51 \%$ of the relationship between gratitude and stress, and $11 \%$ of the relationship between gratitude and satisfaction with life. However, there was no evidence for any mediation of the relationship between gratitude and either happiness or depression, or full mediation between gratitude and any of the well-being measures. To our knowledge, this is the first study to show that the grateful personality is linked to coping styles, one of the first studies to show that grateful people have a differential profile of psychological resources in areas other than well-being, and the first to show any partial mechanism whereby gratitude is related to well-being.

\section{GRATITUDE AND COPING}

Regarding the correlations between gratitude and coping, the results showed three main trends. First, there was considerable similarity 
across the two samples. Second, grateful people were more likely to seek out emotional and instrumental social support as a means of coping. Third, grateful people generally used more positive coping strategies, which seem broadly characterised by approaching the problems (using positive reinterpretation and growth, active coping, and planning) rather than avoiding the problems (behavioural disengagement, self-blame, substance use, and denial).

The association between gratitude and the seeking out of emotional and instrumental social support is in line with conceptions of gratitude as a socially oriented personality trait. Whilst there is considerable evidence regarding the pro-social basis of the grateful emotion (McCullough et al., 2001; Tesser et al., 1968; Tsang, 2006), the current study provides some of the earliest support for the pro-social basis of the grateful disposition (as suggested by McCullough et al., 2002).

Gratitude was related to generally more positive coping, being associated with strategies that involve approach rather than withdrawal tendencies. We had previously hypothesised this relationship as positive coping strategies seemed likely to be a benefit which would arise from the frequent experience of gratitude (c.f. Fredrickson, 1998, 2001, 2004), and as grateful people have been shown to view the world as a more pleasant and hospitable place (Adler \& Fagley, 2005; Watkins et al., 2003). Notably, we found that gratitude was not positively correlated to a single negative coping strategy, or negatively correlated with any positive strategy.

\section{PARTIAL MEDIATION}

In line with previous research, gratitude was related to higher levels of happiness and satisfaction with life, and lower levels of stress and depression. The results suggested that coping could be a partial mediator of the relationship between gratitude and stress, and to a lesser extent the relationship between gratitude and satisfaction with life. In the first sample, $51 \%$ of the relationship between gratitude and stress was mediated by behavioural disengagement, positive reinterpretation and growth, and self-blame. It seems that grateful people utilise more positive coping strategies, which lower the levels of stress that they experience.

There was, however, no evidence of partial mediation for either happiness or depression, and a very small mediation for satisfaction with life (11\%) by self-blame. Whilst coping may play an important role in explaining why grateful people experience less stress, it seems that coping is not the primary mechanism whereby gratitude is related to well-being. This is interesting, given that coping styles are known to substan- 
tially mediate the relationship between well-being and other positive traits such as optimism (Brissette et al., 2002), and it seemed likely that a similar process may occur with gratitude. It does not seem likely that the results occurred because of issues with data integrity, given that we replicated earlier findings regarding the relationship between gratitude and well-being; there was a high level of consistency between our two samples; and the association between gratitude and coping style was in line with our predictions. Rather, this finding tends to support evidence that the grateful disposition is distinct from other related personality traits (such as optimism) (c.f. McCullough et al., 2002), and suggests that gratitude is related to well-being through different mechanisms than related constructs. It also seems that there may be different mechanisms relating gratitude to different aspects of well-being.

\section{LIMITATIONS}

As we used two samples from a college student population, it is of course possible that gratitude is differently related to coping strategies in other populations, particularly those facing higher levels of stress and adversity, and those with distinct clinical and health needs. Coping styles may more strongly mediate the relationship between gratitude and well-being in these populations. We recommend a programme of research into this possibility, and hope that the current study will be helpful in stimulating and designing this research. However, most previous research into gratitude and well-being has been with non-clinical populations, typically college students. Consistent with the positive psychology movement (see Linley et al., 2006), we are equally as interested in understanding well-being in the general population as we are with understanding populations undergoing distress.

The correlational and cross-sectional nature of the study prevents conclusions being drawn regarding causality between gratitude and coping. It seems likely that gratitude will lead to more positive coping strategies for the reasons discussed in the introduction, but this could be more clearly established by future experimental or longitudinal research.

The self-report nature of the study raises the possibility that social desirability may have inflated both reports of gratitude and positive coping. Against this possibility are McCullough's (2002) findings that the self-report of gratitude is substantially related to peer report, not highly correlated with social desirability, and controlling for social desirability does not substantially change the relationship between the self-reports of gratitude and either well-being, social, or personality variables. How- 
ever the possibility of a social desirability bias would be better addressed through future experimental work.

\section{FUTURE DIRECTIONS}

Multiple new research questions emerge from this research, in addition to the role of gratitude and coping in clinical populations, and whether positive coping is facilitated by gratitude interventions. For example, the finding that gratitude is related to social support coping suggests that gratitude may be involved in other aspects of social support. Perceptions of the availability of social support are distinct to social support coping, with the former representing beliefs that one is cared about and valued enough by other people for them to provided help should it be needed (Pierce, Baldwin, \& Lydon, 1997). Enacted social support represents what help people objectively receive in situations, and is distinct from self-perceptions of social support (Lakey \& Drew, 1997). Each of these aspects of social support have extensive research literatures which have yet to be integrated with research into the grateful personality, and both lines of inquiry naturally arise from the current study. Further, the association between gratitude and positive reinterpretation and growth suggests that gratitude may be involved in psychological growth following trauma (see Linley \& Joseph, 2004), although to our knowledge this remains to be investigated.

The mediation between gratitude and stress was partial, and there was little or low mediation between gratitude and either happiness, depression, or satisfaction with life. As such future research should examine what other mechanisms mediate the relationship between gratitude and well-being. The current study suggests several potential mechanisms. As noted above, research is indicated into the relationship between gratitude and social support. Social support mediates the relationship between well-being other positive traits such as optimism (Brissette et al., 2002), and this may also be the case for gratitude. Grateful people were also shown to engage in less self-blame, which perhaps implicates a relationship between gratitude and self-esteem, another potential mediator. The present finding that gratitude partially mediates the relationship between gratitude and stress suggests that the relationship between gratitude and well-being is not necessarily direct, and underlines the importance of looking for other mediating mechanisms.

\section{CONCLUSION}

In this study, we found that grateful people were more likely to seek out emotional and instrumental social support, and used coping strategies 
that were broadly characterised by approaching the problem, rather than avoiding the problem. Additionally, the results suggest coping strategies may be an important mechanism explaining why gratitude is negatively related to stress, although coping strategies do not appear to be the primary mechanism by which gratitude is related to other well-being variables. Gratitude research remains embryonic, and the findings reported here suggest that gratitude has distinct contributions to make to our understanding of the personality and individual difference variables that may influence health and well-being. As such, there are many exciting future directions for research into the grateful disposition.

\section{REFERENCES}

Adler, M. G., \& Fagley, N. S. (2005). Appreciation: Individual differences in finding value and meaning as a unique predictor of subjective well-being. Journal of Personality, 73, 79-114.

Baron, R. M., \& Kenny, D. A. (1986). The moderator-mediator variable distinction in social psychological research: Conceptual, strategic, and statistical considerations. Journal of Personality and Social Psychology, 51, 1173-1182.

Bartlett, M. Y., \& DeSteno, D. (2006). Gratitude and prosocial behavior: Helping when it costs you. Psychological Science, 17, 319-325.

Beck, A. T. (1976). Cognitive therapy and the emotional disorders. Oxford, England: International Universities Press.

Bono, G., Emmons, R. A., \& McCullough, M. E. (2004). Gratitude in practice and the practice of gratitude. In P. A. Linley \& S. Joseph (Eds.), Positive psychology in practice (pp. 464-481). Hoboken, NJ: John Wiley \& Sons, Inc.

Brissette, I., Scheier, M. F., \& Carver, C. S. (2002). The role of optimism in social network development, coping, and psychological adjustment during a life transition. Journal of Personality and Social Psychology, 82, 102-111.

Carver, C. S. (1997). You want to measure coping but your protocol's too long: Consider the brief COPE. International Journal of Behavioral Medicine, 4, 92-100.

Carver, C. S., Scheier, M. F., \& Weintraub, J. K. (1989). Assessing coping strategies - a theoretically based approach. Journal of Personality and Social Psychology, 56, 267-283.

Cohen, S., Kamarck, T., \& Mermelstein, R. (1983). A global measure of perceived stress. Journal of Health and Social Behavior, 24, 385-396.

Cohen, S., \& Williamson, G. (1988). Perceived stress in a probability sample of the United States. In S. Spacapam \& S. Oskamp (Eds.), The social psychology of health. Newbury Park, CA: Sage.

Duckworth, A. L., Steen, T. A., \& Seligman, M. E. P. (2005). Positive psychology in clinical practice. Annual Review of Clinical Psychology, 629-651.

Emmons, R. A., \& Crumpler, C. A. (2000). Gratitude as a human strength: Appraising the evidence. Journal of Social and Clinical Psychology, 19, 56-69.

Emmons, R. A., \& McCullough, M. E. (2003). Counting blessings versus burdens: An experimental investigation of gratitude and subjective well-being in daily life. Journal of Personality and Social Psychology, 84, 377-389. 
Fredrickson, B. L. (1998). What good are positive emotions? Review of General Psychology, 2, 247-270.

Fredrickson, B. L. (2000). Cultivating positive emotions to optimize health and well-being. Prevention and Treatment, 3, Article 0001a.

Fredrickson, B. L. (2001). The role of positive emotions in positive psychology-The broaden-and-build theory of positive emotions. American Psychologist, 56, 218-226.

Fredrickson, B. L. (2004). Gratitude, like other positive emotions, broadens and builds. In R. A. Emmons \& M. E. McCullough (Eds.), The Psychology of Gratitude (pp. 145-166). New York: Oxford University Press.

Fredrickson, B. L., \& Branigan, C. (2005). Positive emotions broaden the scope of attention and thought-action repertoires. Cognition \& Emotion, 19, 313-332.

Fredrickson, B. L., Tugade, M. M., Waugh, C. E., \& Larkin, G. R. (2003). What good are positive emotions in crises? A prospective study of resilience and emotions following the terrorist attacks on the United States on September 11th, 2001. Journal of Personality and Social Psychology, 84, 365-376.

Gallup. (1999). Survey results on "gratitude," adults and teenagers. Emerging Trends, 20, $4-5,9$.

Gordon, R. A. (1968). Issues in multiple regression. American Journal of Sociology 73, 592-616.

Harpman, E. J. (2004). Gratitude in the history of ideas. In R. A. Emmons \& M. E. McCullough (Eds.), The psychology of gratitude (pp. 19-36). New York: Oxford University Press.

Johnson, K. J., \& Fredrickson, B. L. (2005). “We all look the same to me" - Positive emotions eliminate the own-race bias in face recognition. Psychological Science, 16, 875-881.

Joseph, S., \& Linley, P. A. (2006). Positive therapy: A meta-theory for positive psychological practice. New York: Routledge.

Joseph, S., Linley, P. A., Harwood, J., Lewis, C. A., \& McCollam, P. (2004). Rapid assessment of well-being: The Short Depression-Happiness Scale. Psychology and Psychotherapy: Theory, Research, and Practice, 77, 1-14.

Kenny, D. A., Kashy, D. A., \& Bolger, N. (1998). Data analysis in social psychology. In D. T. Gilbert, S. T. Fiske \& G. Lindzey (Eds.), The handbook of social psychology (pp. 233-265). New York: McGraw-Hill.

Lakey, B., \& Drew, J. B. (1997). A social-cognitive perspective on social support. In G. R. Pierce, B. Lakey, I. G. Sarason \& B. R. Sarason (Eds.), Sourcebook of social support and personality (pp. 107-140). New York: Plemum Press.

Linley, P. A., \& Joseph, S. (2004). Positive change following trauma and adversity: A review. Journal of Traumatic Stress, 17, 11-21.

Linley, P. A., Joseph, S., Harrington, S., \& Wood, A. M. (2006). Positive psychology: Past, present, and (possible) future. The Journal of Positive Psychology, 1, 3-16.

Lyubomirsky, S., Sheldon, K. M., \& Schkade, D. (2005). Pursuing happiness: The architecture of sustainable change. Review of General Psychology, 9, 111-131.

Maddux, J. E. (2002). Stopping the 'madness': Positive psychology and the deconstruction of the illness ideology and the DSM. In C. Snyder \& S. J. Lopez (Eds.), Handbook of Positive Psychology (pp. 13-25). New York: Oxford University Press.

Maddux, J. E., Gosselin, J. T., \& Winstead, B. A. (2005). Conceptions of psychopathology: A social constructionist perspective. In J. E. Maddux \& B. A. Winstead (Eds.) Psychopathology: Foundations for a contemporary understanding (pp. 3-18). New York: Lawrence Erlbaum Associates.

Maddux, J. E., Snyder, C. R., \& Lopez, S. J. (2004). Toward a positive clinical psychology: Deconstructing the illness ideology and constructing an ideology of human strengths and potential. In P. A. Linley \& S. Joseph (Eds.), Positive psychology in practice. Hoboken, NJ. Wiley. 
McCullough, M. E., Emmons, R. A., \& Tsang, J. A. (2002). The grateful disposition: A conceptual and empirical topography. Journal of Personality and Social Psychology, 82, $112-127$.

McCullough, M. E., Kilpatrick, S. D., Emmons, R. A., \& Larson, D. B. (2001). Is gratitude a moral affect? Psychological Bulletin, 127, 249-266.

McCullough, M. E., Tsang, J.-A., \& Emmons, R. A. (2004). Gratitude in intermediate affective terrain: Links of grateful moods to individual differences and daily emotional experience. Journal of Personality and Social Psychology, 86, 295-309.

Park, N., Peterson, C., \& Seligman, M. E. P. (2004). Strengths of character and well-being. Journal of Social and Clinical Psychology, 23, 603-619.

Paulhus, D. L. (1998). Interpersonal and intrapsychic adaptiveness of trait self-enhancement: A mixed blessing? Journal of Personality and Social Psychology, 74, 1197-1208.

Pavot, W., \& Diener, E. (1993). Review of the Satisfaction With Life Scale. Psychological Assessment, 5, 164-172.

Peterson, C., \& Seligman, M. E. P. (2004). Character strengths and virtues: A handbook and classification. New York: Oxford University Press.

Pierce, T., Baldwin, M. W., \& Lydon, J. E. (1997). A relational scheme to social support. In G. R. Pierce, B. Lakey, I. G. Sarason \& B. R. Sarason (Eds.), Sourcebook of social support and personality (pp. 19-49). New York: Plemum Press.

Ptacek, J. T., \& Gross, S. (1997). Coping as an individual difference variable. In G. R. Pierce, B. Lakey, I. G. Sarason \& B. R. Sarason (Eds.), Sourcebook of social support and personality (pp. 69-92). New York: Plenum Press.

Radloff, L. S. (1977). The CES-D scale: A self-report depression scale for research in the general population. Applied Psychological Measurement, 1, 385-401.

Schwarzer, R., \& Schwarzer, C. (1996). A critical survey of coping instruments. In M. Zeidner \& N. S. Endler (Eds.), Handbook of coping - theory, research, applications (pp. 107-132). New York: Wiley.

Seligman, M. E., \& Csikszentmihalyi, M. (2000). Positive psychology: An introduction. American Psychologist, 55, 5-14.

Seligman, M. E., Steen, T. A., Park, N., \& Peterson, C. (2005). Positive psychology progress: Empirical validation of interventions. American Psychologist, 60, 410-421.

Somerfield, M. R., \& McCrae, R. R. (2000). Stress and coping research - Methodological challenges, theoretical advances, and clinical applications. American Psychologist, $55,620-625$.

Sternberg, R. J., \& Grigorenko, E. L. (2001). Unified psychology. American Psychologist, 56, 1069-1079.

Tesser, A., Gatewood, R., \& Driver, M. (1968). Some determinants of gratitude. Journal of Personality and Social Psychology, 9, 233-236.

Tsang, J.-A. (2006). Gratitude and prosocial behaviour: An experimental test of gratitude. Cognition \& Emotion, 20, 138-148.

Watkins, P. C., Woodward, K., Stone, T., \& Kolts, R. L. (2003). Gratitude and happiness: Development of a measure of gratitude, and relationships with subjective well-being. Social Behavior and Personality, 31, 431-451.

Wood, A. M., Joseph, S., \& Linley, P. A. (2007). Gratitude: The parent of all virtues. The Psychologist, 20, 18-21. 
Copyright of Journal of Social \& Clinical Psychology is the property of Guilford Publications Inc. and its content may not be copied or emailed to multiple sites or posted to a listserv without the copyright holder's express written permission. However, users may print, download, or email articles for individual use. 